\title{
Analysis of Industrial Ecological Compensation in Gansu Province Based on Input-output Method
}

\author{
Chunyan Li \\ College of Geographic and Environment Science \\ Northwest Normal University \\ Lanzhou, China 730070
}

\author{
Zhong Ma \\ College of Geographic and Environment Science \\ Northwest Normal University \\ Lanzhou, China 730070
}

\begin{abstract}
From the perspective of regional coordinated development, the theory of ecological compensation between Gansu Province and other provinces is applied. Based on the input-output table of China in 2012, this paper uses the inputoutput method to calculate and analyze the land resource occupancy of Gansu Province and other inter-provincial industries in China. It takes the statistical data as an example. The results show that: First, from the perspective of consumption, the land resources occupancy of each province in Gansu Province is calculated, and it is concluded that the provinces in the central and Eastern regions, such as Shanghai, Zhejiang, Jiangsu, Chongqing, Fujian, Guangdong, Beijing, Anhui and other cities with high economic level, occupy more land resources in Gansu Province, and the eight sectors of industries in Gansu Province belong to occupied industries. The economic development of Gansu Province should be compensated. Second, by calculating the amount of land resources occupied by provinces in Gansu Province from the perspective of investment, it is concluded that the amount of land resources occupied by provinces differs greatly. Generally speaking, under the investment scenario, the amount of resources occupied by provinces in Gansu Province is relatively small, but from the perspective of region, the eastern developed provinces and cities should become the main body to undertake the ecological compensation. Third, from the point of view of export and investment, the land resources occupied by each province in Gansu Province are estimated. All the 8 sectors of industries belong to occupied industries. Moreover, the resources occupied by each province in Gansu Province are more, and the occupancy of central and eastern provinces is larger. Therefore, more ecological compensation should be undertaken in order to coordinate the stable development of the whole country. Finally, from the aspects of strengthening the legislation of industrial ecological compensation and perfecting the tax means of industrial ecological compensation, the relevant policy suggestions are put forward.
\end{abstract}

Keywords-industrial ecology; input-output; land occupation; Gansu Province

\section{INTRODUCTION}

In order to promote the transfer of industries in the eastern region to the central and western regions, China has implemented a series of regional development strategies and found that the regional development gap between the eastern and central regions has not been narrowed but widened. Therefore, regional coordinated development is still one of the important issues facing China's regional development. While in the practice, the contradiction between economic development and environmental protection in the western region is prominent, which limits the economic development of this region. As an innovative environmental protection measure, ecological compensation is also a policy tool to deal with environmental and economic problems around the world. [2] At present, foreign research on ecological compensation begins with Costa Rica's "PES" (PES refers to the Payment for Environmental Service or Payment for Ecosystem Service). Its macro research framework clarifies the main content of ecological compensation from three aspects: ecological, economic and policy design. The research of ecological compensation in China is partly the references and summary of the theories and methods of ecological compensation in western countries, and the other part is the summary of the theories and methods of ecological compensation engineering in China [8] [9].

As human beings destroy the ecological environment, it is mainly reflected in industrial activities. Therefore, industry is an important field of ecological compensation. With the implementation of China's circular economy development strategy, industrial ecologicalization has achieved certain results in theoretical research and industrial practice. However, there are many problems in the profit-driven mechanism, incentive mechanism and coordination mechanism, so the promotion of regional industrial ecological compensation system is urgently needed. Since the 1990s, China has introduced relevant ecological compensation mechanisms in the exploration and practice of regional ecological compensation [4]. In 2017, the "Decision of the Central Committee of the Communist Party of China on Comprehensively Deepening the Reform of Some Major Issues" pointed out: "The government will implement the system of compensated use of resources and the system of ecological compensation, and adhere to the principle of who benefits, who compensates. It's also necessary to improve the mechanism of ecological compensation for key ecological functional zones, and promote the establishment of a system of horizontal ecological compensation among different regions [6] [7]. Therefore, regional industrial ecological compensation is the only way to achieve a win-win situation between industrial development and regional environmental protection, and it is an important research and practice area of ecological compensation. 
In the estimation of ecological compensation, the research method of economics is often adopted, and the research is carried out with a single geographical unit as the research object, but with a weak practical feasibility. Due to the complexity and concealment of ecosystems and the interrelationships among regions, it's necessary to interact with each other through various economic flows. And then judge the relationship between occupy ecological resources and be occupied ecological resources, which is also an important aspect of the mutual contact and interaction among regions. Input-output (IO) technology is a systematic and comprehensive analysis of the economic and environmental relationship among regions. The input-output table is also a balance table that reflects the relationship among different regional departments in a certain period of time. It has been well applied in researching carbon emissions, household carbon footprint, water footprint, industrial linkage impact and industrial structure upgrading [5]. Some scholars have tried to use the method of input-output (I-O) to conduct research in ecological compensation. [10] [11] [12] [13] [14]. However, they are all used for input-output technology to perform accounting analysis on a specific natural resource. For example, the measurement framework of rice field ecological compensation standards was constructed based on the willingness of farmers to compensate and the government's input and output analysis of compensation funds. [13] In addition, Liu Chunla and other scholars also used the input-output technology to analyze the natural resource occupation among different provinces at the national level [15]. While it uses the input-output technology to account for the occupation of land natural resources in Gansu Province and other provinces, in order to provide decision support and scientific reference for the implementation of regional ecological compensation policy, which is the innovative direction for ecological compensation research.

\section{OVERVIEW OF RESEARCH AREAS}

Gansu Province is located in the northwestern part of China. The three natural geographical regions of the eastern monsoon region, the northwest arid region and the QinghaiTibet Plateau are meeting here. In the west of the Yellow River in Gansu province, there is a unique natural corridor from Wushaoling in the east to the Old Jade Gate Pass in the west. However, this region is located in the arid and semiarid areas in the west region, where the climate is dry, the natural conditions are harsh, and the ecological environment is extremely sensitive and fragile. Therefore, the development of economy and the building of a moderately prosperous society are restricted by water resources and ecological environment. In recent years, China's economic development and ecological environmental protection have been highly contradictory, especially in the ecologically fragile western provinces. Therefore, ecological compensation is a way to adjust the economic interests of related subjects and the interests of ecological environment [16]. It can not only mediate the interests of various relevant entities and coordinate the development of various regions or departments, but also curb the deteriorating momentum of China's ecological environment, ensure the sustainable development of the environment and economy and society, and mediate the interests of the relevant regional entities.

\section{LOGICAL FRAMEWORK}

According to the regional ecological compensation theory, from the perspective of regional relations, if the development of a region occupies the ecological resources of other regions, it should be compensated for the areas where the ecological resources are occupied; on the contrary, if one region contributes the ecology resources to other regions and deserves compensation.

In the input-output analysis among multiple regions, due to the different final demand items of investment, consumption and export, there are various interactions between resources and economy in the inter-regional areas, and there are bound to be (virtual) ecological resources occupy and be occupied situations among regions. The ecological status of Gansu Province is very important. Gansu Province has been identified as the National Circular Economy Experimental Zone, the National Ecological Safety Barrier Construction, Protection and Compensation Comprehensive Experimental Zone in recent years. Although the economy of Gansu province is backward, it still can't develop the economy at the cost of environment and develop resources wantonly, so as to achieve harmonious development among regional economies. This has led to a reduction in the economic gap between the central and western regions. While other provinces develop their economies, they also occupy ecological resources in Gansu Province to a certain extent, so they should compensate Gansu Province.

\section{RESEARCH METHODS AND DATA}

\section{A. Methods and Steps}

Under the analytical framework of input-output (Liu Hongguang et al., 2001), based on the non-competitive interregional value input-output table:

$$
X=\left(I-A^{d}\right)-1 \times\left(Y_{E}+Y_{C}+Y_{I}+Y_{O}\right)(1)
$$

In the formula (1): $X$ is the domestic total output column vector, $A^{d}$ is the direct consumption coefficient matrix, $Y_{E}$, $Y_{O}, Y_{I}$, and ${ }^{Y_{C}}$ are respectively the consumption item, the export item, investment items and other items in the inputoutput table.

The Leonidfu inverse matrix $\left(I-A^{d}\right)^{-1}$ of the domestic intermediate input is recorded as $B$. It is assumed that there are $m$ regions in each country (each region has $n$ departments), and it is introduced into Gansu under the framework of national environmental input and output analysis. The total output (value) of each industrial unit in the province is directly related to the direct occupation coefficient of the land ecological 
resources $F=f_{1}, \cdots, f_{n}^{1}, \cdots, f_{1}^{m}, \cdots, f_{n}^{m}$, It is diagonalized and can obtain the ecological resources caused by the different final demand of consumption, export and investment between Gansu Province and other provinces. Occupy matrix mathematical $C, V, Z$ :

$$
\begin{aligned}
& C=\hat{F} \cdot B \cdot \hat{Y}_{E} \\
& V=\hat{F} \cdot B \cdot \hat{Y}_{C} \\
& Z=\hat{F} \cdot B \cdot \hat{Y}_{I}
\end{aligned}
$$

In equations (2) (3) (4): $C, V$, and $Z$ are shorthand for $C_{i j}^{g q}, V_{i j}^{g q}$, and $Z_{i j}^{g q}$, that is, $q$ regional industrial $j$ departments, consumption, exports, and investment caused by Gansu Province. ( $g$ ) $i$. The ecological resources occupied by the industrial sector. Through formulas (2), (3), (4), it is possible to determine the specific matrix elements and the specific resources of specific industries in the relevant regions.

$$
C_{\text {netil }}^{r s}=C_{i j}^{\text {gq }}+V_{i j}^{\text {gq }}+Z_{i j}^{\text {gq }}
$$

In the formula (5): ${ }^{\text {retil }}$ shows the total land occupation of the industrial departments of Gansu Province caused by the export, consumption and investment of all industries in other provinces across the country.

\section{B. Data Source}

This paper takes China's provinces and regions as the research unit (it's difficult to obtain the data in Hong Kong, Macao, and Taiwan, and the regional input-output tables in 2012 doesn't include these three regions), and explores the ecological resources in the provinces in 2012. There also exists the occupation situation (for example, the land resources). The land area data of the eight industrial sectors (agriculture, forestry, animal husbandry, fishery, industry, construction, transportation and warehousing, wholesale and retail, accommodation and catering, information transmission, software and information technology services, and other services) in Gansu Province are mainly from the source in China Land and Resources Yearbook 2012, China Statistical Yearbook 2012, China Environmental Statistics Yearbook 2012, Gansu Yearbook 2012. The 2012 interregional input-output table was derived from the 2012 Interregional Input-Output Table of 31 Provinces and Cities in China issued by the Key Laboratory of Regional Sustainable Development Analysis and Simulation of the Chinese Academy of Sciences.

\section{RESULTS AND ANALYSIS}

It can be calculated that the land resource occupation relationship and occupation amount of six major industries in each province to Gansu province in 2012.

\section{A. Consumption Caused by the Consumption of Land Resources in Gansu Province}

From the point of view of consumption, the characteristics of various industries in various provinces and cities for the occupation of land resources in Gansu Province are as follows: First, agriculture, forestry, animal husbandry and fishery are belonging to the type of land resources occupied. Anhui, Heilongjiang, Hainan, Henan, Shaanxi, Shandong and other places, their agricultural economic development is relatively advanced, and the agricultural land resources in Gansu Province are relatively large; Guizhou, Jiangsu, Jiangxi, Liaoning, Hebei, Yunnan, Fujian, Chongqing, Guangdong, Guangxi, Beijing, Hunan and other eastern and central provinces have occupied of agriculture, forestry, animal husbandry and fishery in Gansu Province is between 1000 and $4000 \mathrm{~cm}^{2}$; the remaining provinces in Sichuan, Shanghai, Shanxi, Xinjiang and other places have less occupation. Especially in the three provinces of Tibet, Ningxia and Qinghai, the land occupation is less than 200, and the occupation of agricultural land resources in Gansu Province is an important basis for the development of other industries in other provinces. Second, industry belongs to the type of industry that occupies land resources. In the early days of Gansu's development, the state invested a lot of basic heavy chemical industry in Gansu Province, so the industry occupied more land resources. As can be seen from "Fig. 1", industries in Henan, Shandong, Guangdong, Jilin, Fujian, Chongqing, Anhui, Shanghai, Zhejiang, and Jiangsu have more land occupations in Gansu Province, except for the three provinces of Tibet, Xinjiang, and Qinghai. Other provinces also have more land resources for industries in Gansu Province. These provinces have a large demand for basic industrial products in Gansu Province, and they are related to factors such as policy orientation of industrial development and economic infrastructure. Third, in terms of construction industry, under the background of consumption, land resources are closely related to population, economic development level of the region, development status of construction industry, and real estate policies of the region. Therefore, as the economic level of Gansu Province is higher than Qinghai, Tibet, the Pearl River Delta and the Yangtze River Delta, the development is at an equal level, the house prices are not high, and the law of geographical differentiation is not obvious. Therefore, it belongs to the land resources occupying other provinces. Fourth, a transportation industry is a type of land resource occupation. The six regions of Inner Mongolia, Guangdong, Jiangsu, Zhejiang, Beijing and Shanghai occupy a large proportion of their land resources, followed by Hainan, Guangxi, Xinjiang, Shanxi, Hunan, Chongqing and Shaanxi. The occupancy of Shandong, Hebei, Hubei, Fujian, Liaoning, Sichuan, Anhui, and Tianjin is moderate, and Ningxia, Qinghai, Yunnan, Tibet, Guizhou, Henan, and Jilin are less occupied. Fifth, in the accommodation, catering, information transmission, software and information technology services and other services, Tianjin, Jiangsu, Neimenggu, Sichuan, Zhejiang, Shanghai, Beijing and other places have more land resources in Gansu Province, the remaining provinces are shown in "Fig. 1". It was shown that the occupancy is relatively small. Generally speaking, the economic development of Gansu 
Province is slower than that of other provinces in the central and eastern regions of the country. The economy belongs to underdeveloped regions, the basic services are relatively backward, and the location conditions are not superior. Therefore, other provinces in these industries have relatively small occupation of Gansu province.

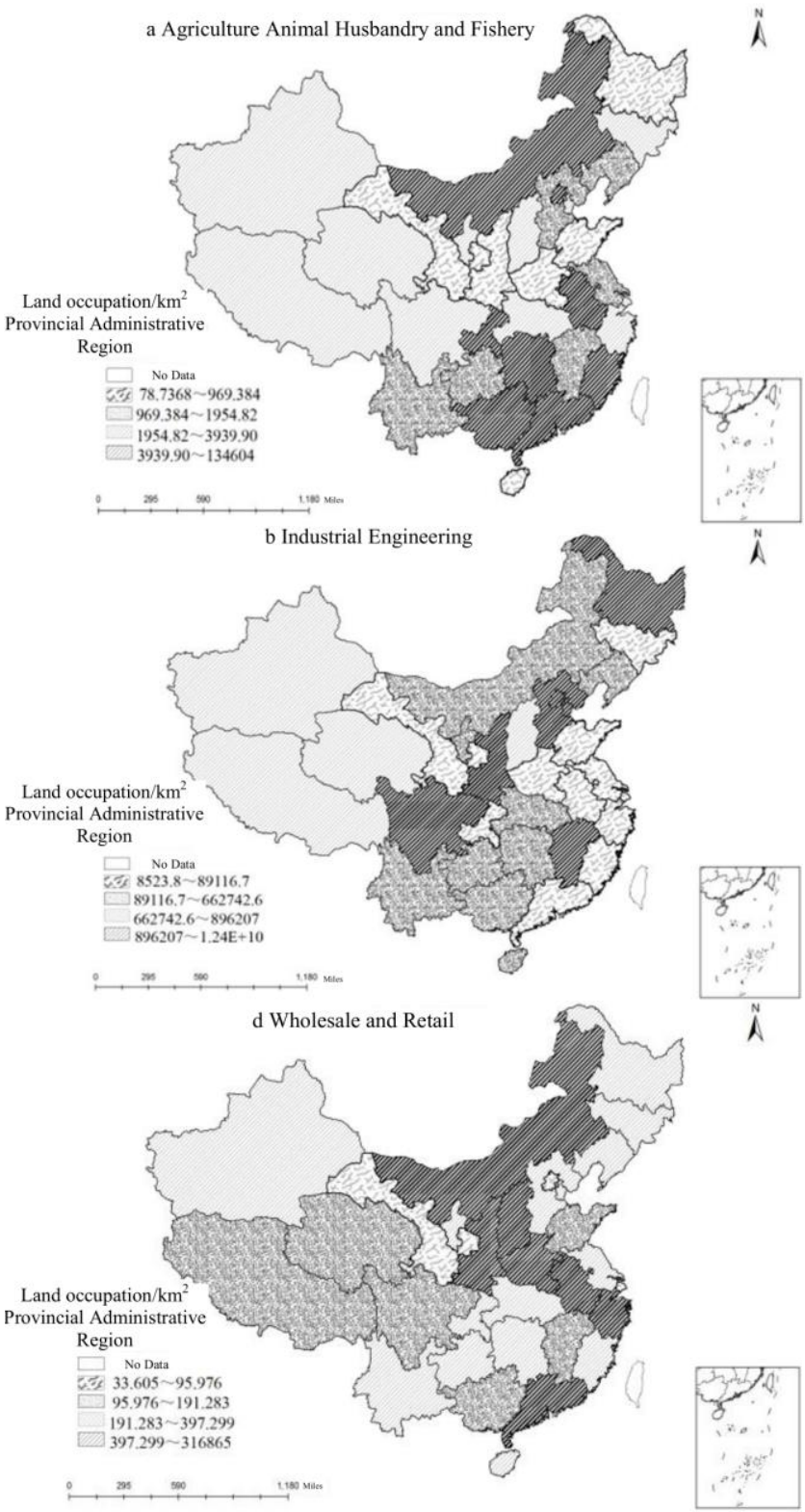

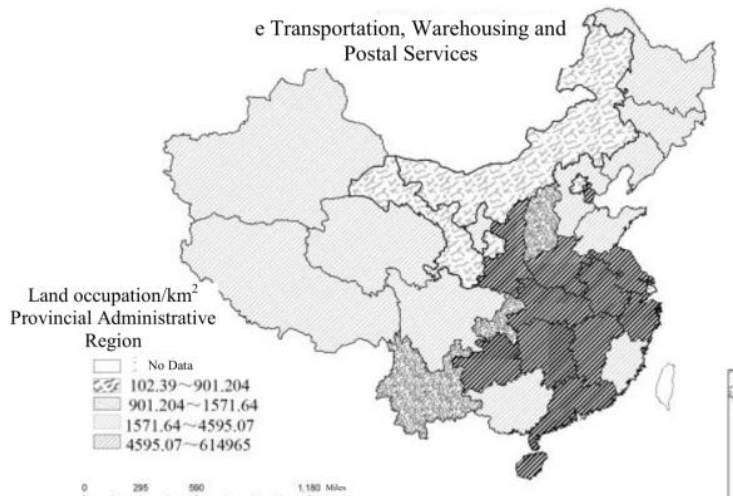

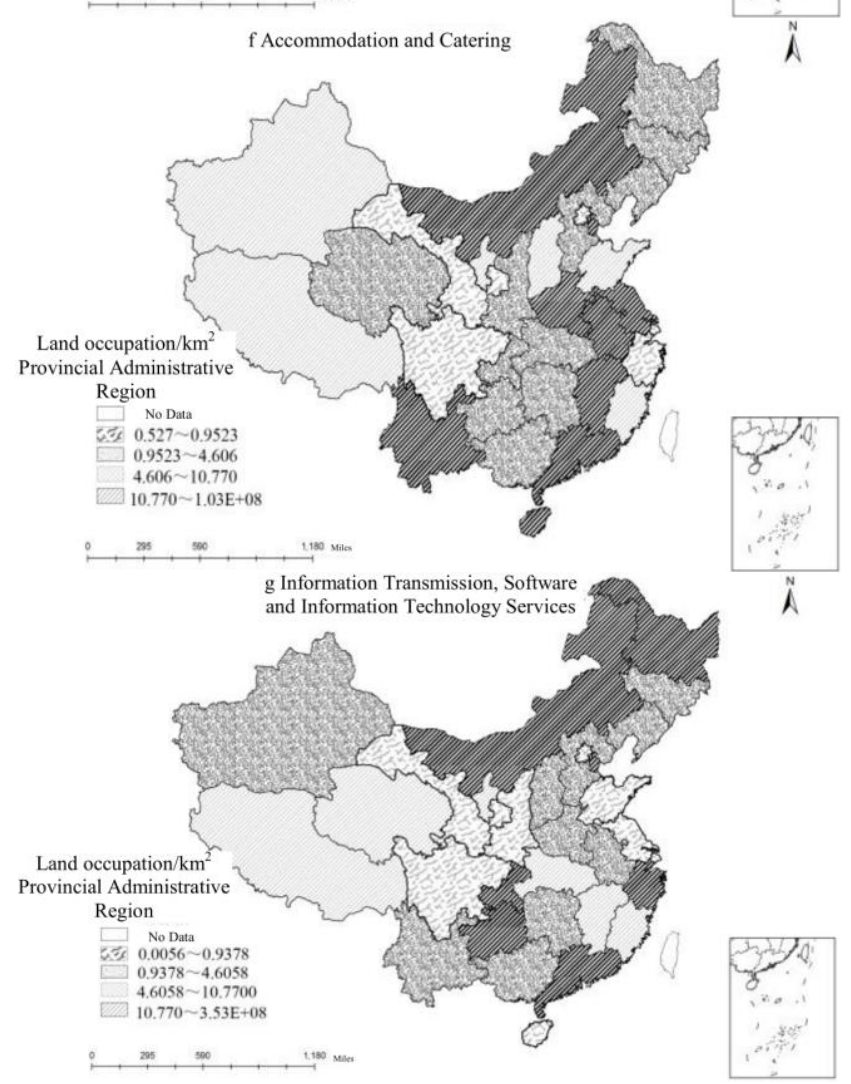




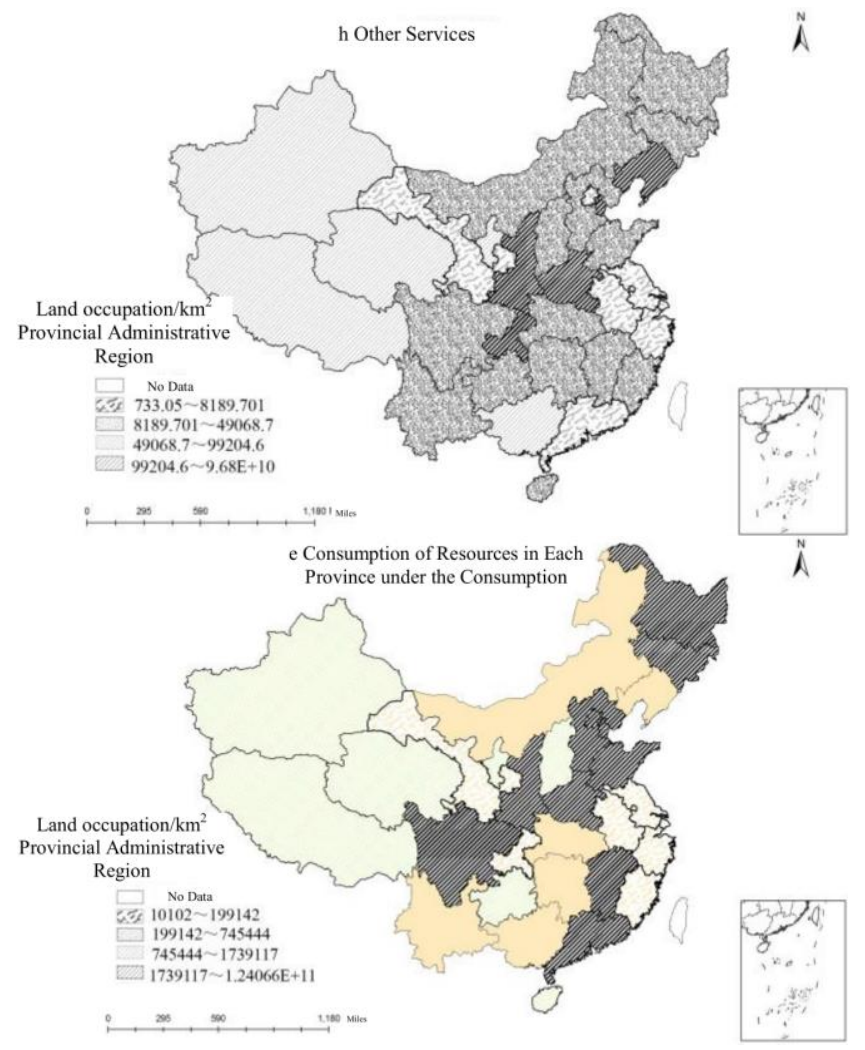

Fig. 1. Land resources occupancy induced by consumption and spatial distribution by sectors in Gansu province.

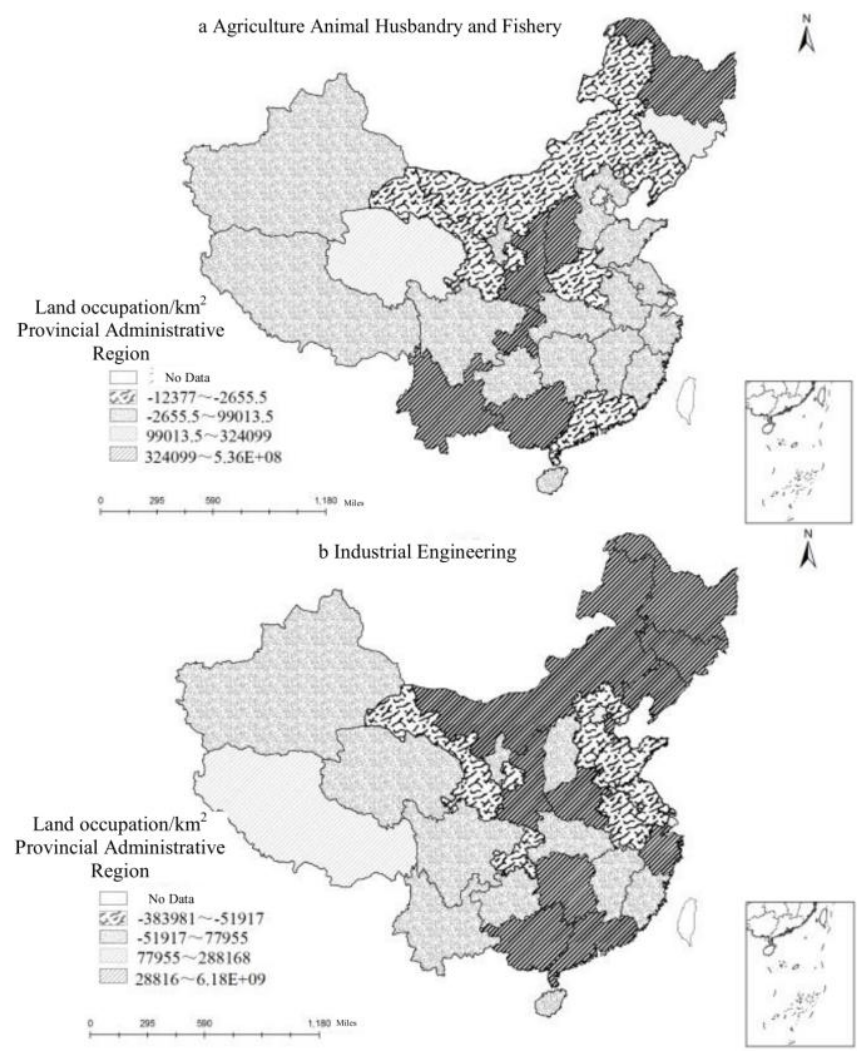

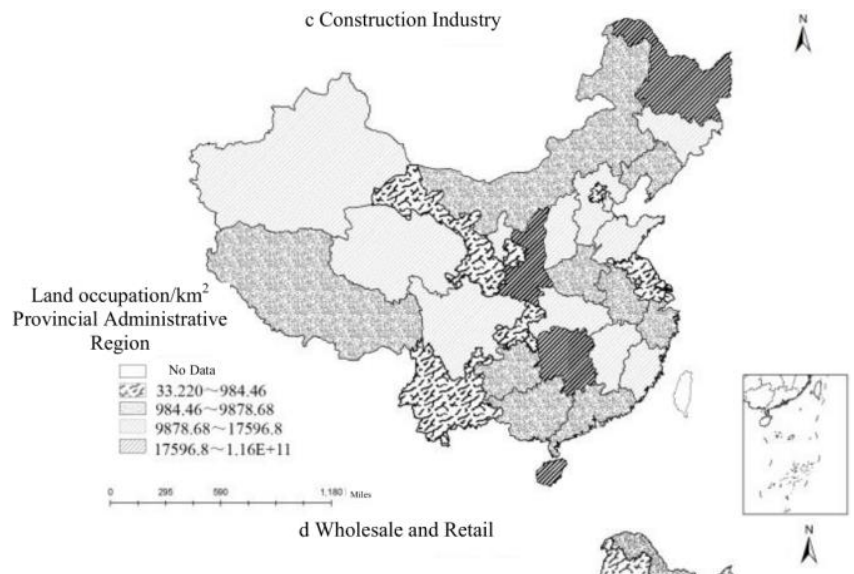

Land occupation $/ \mathrm{km}^{2}$ Provincial Administrative Region

\begin{tabular}{|l}
$\square$ No Data \\
$\square-3273.9 \sim 12.37$ \\
$-12.37 \sim 189.93$ \\
$189.93 \sim 880.23$ \\
$880.23 \sim 1.56 \mathrm{E}+08$
\end{tabular}

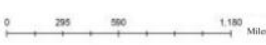

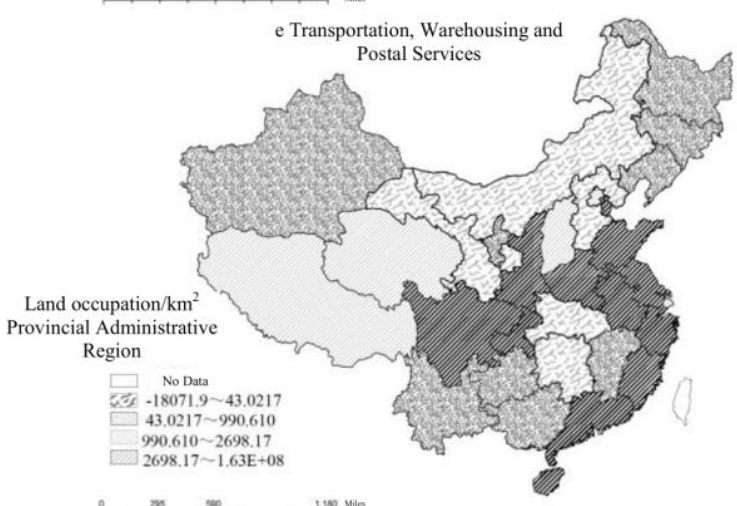

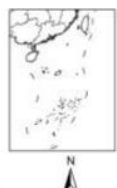

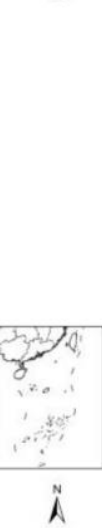

i

Land occupation $/ \mathrm{km}^{2}$ Provincial Administrative Region

\section{द3 $0.00659 \sim 0.42615$ \\ $0.42615 \sim 5.9193$}

$5.9193 \sim 11.968$

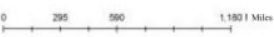

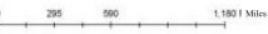

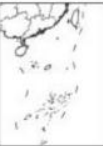




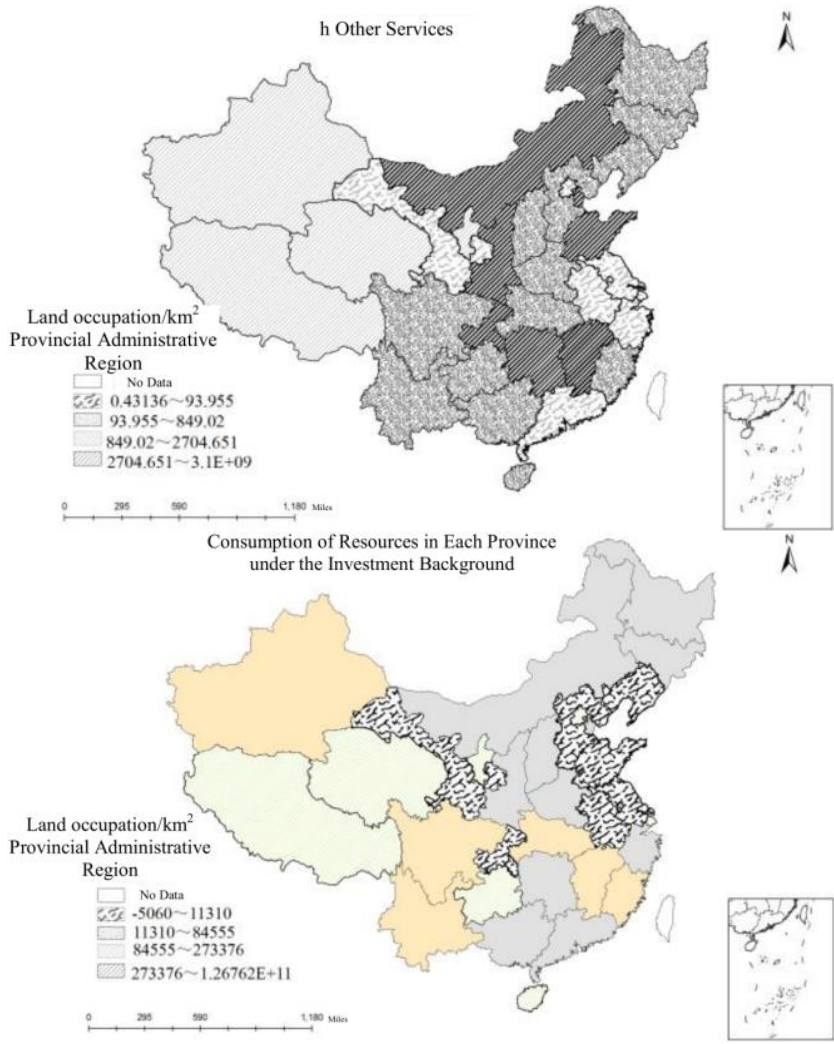

Fig. 2. Land resources occupancy induced by investment and spatial distribution by sectors in Gansu province.

\section{B. The Amount of Land Resources Occupied by Gansu Province Caused by Investment}

From the perspective of investment, the characteristics of various industries' occupation of land resources in Gansu Province are (as shown in "Fig. 2"): First, agriculture, forestry, animal husbandry and fishery belong to the occupied types, Guangxi, Yunnan, Chongqing, Heilongjiang, Shaanxi, Shanxi, Guangdong, Henan, Neimenggu. These provinces in Liaoning have the largest occupancy in Gansu Province, and the provinces of Beijing, Tianjin, Shanghai, Jilin, and Qinghai have negative occupancy rates in Gansu Province, and the remaining provinces have the second largest occupancy. This is mainly related to factors such as regional agricultural base and economic outward type. Second, there are more basic industries in Gansu Province, so the occupations in Gansu Province in Neimenggu, Shaanxi, Guangxi, Heilongjiang, Henan, Tianjin, Guangdong, Zhejiang, Hunan, Jilin, Liaoning, Hebei, Anhui, Chongqing, Shandong and Jiangsu Large, except for the three provinces of Beijing, Shanghai, and Tibet, the occupancy is negative, and the other provinces have a moderate occupancy rate in Gansu Province. Generally speaking, under the investment background, the industrial industry has a relatively large occupation of Gansu Province. Third, the construction industry belongs to the type of land resources occupied. It can be seen from the "Fig. 2" that Hunan, Shaanxi, Heilongjiang, Hainan, Beijing, Chongqing, Shanghai, Yunnan, Jiangsu and other regions with faster development have more occupations in Gansu Province and other provinces took the second place. Shanxi, Qinghai, Sichuan, and Ningxia have the least amount of occupancy. 4 In the wholesale and retail, transportation, warehousing and postal services, information transmission, software and information technology services and some other industries, the occupation of land resources has certain provincial differences. The occupations of Anhui, Shanxi, Beijing, Henan, Xinjiang, Tibet, Guizhou, Ningxia and Qinghai are negative; Shandong, Guangxi, Guangdong, Inner Mongolia, Shanghai, Hubei and Hunan have the largest number of occupations, followed by the remaining provinces. Generally speaking, the provinces with high level of economic development and strong extroverted nature occupy the land resources of Gansu with their transportation and storage industries, wholesale and retail industries and other industries.

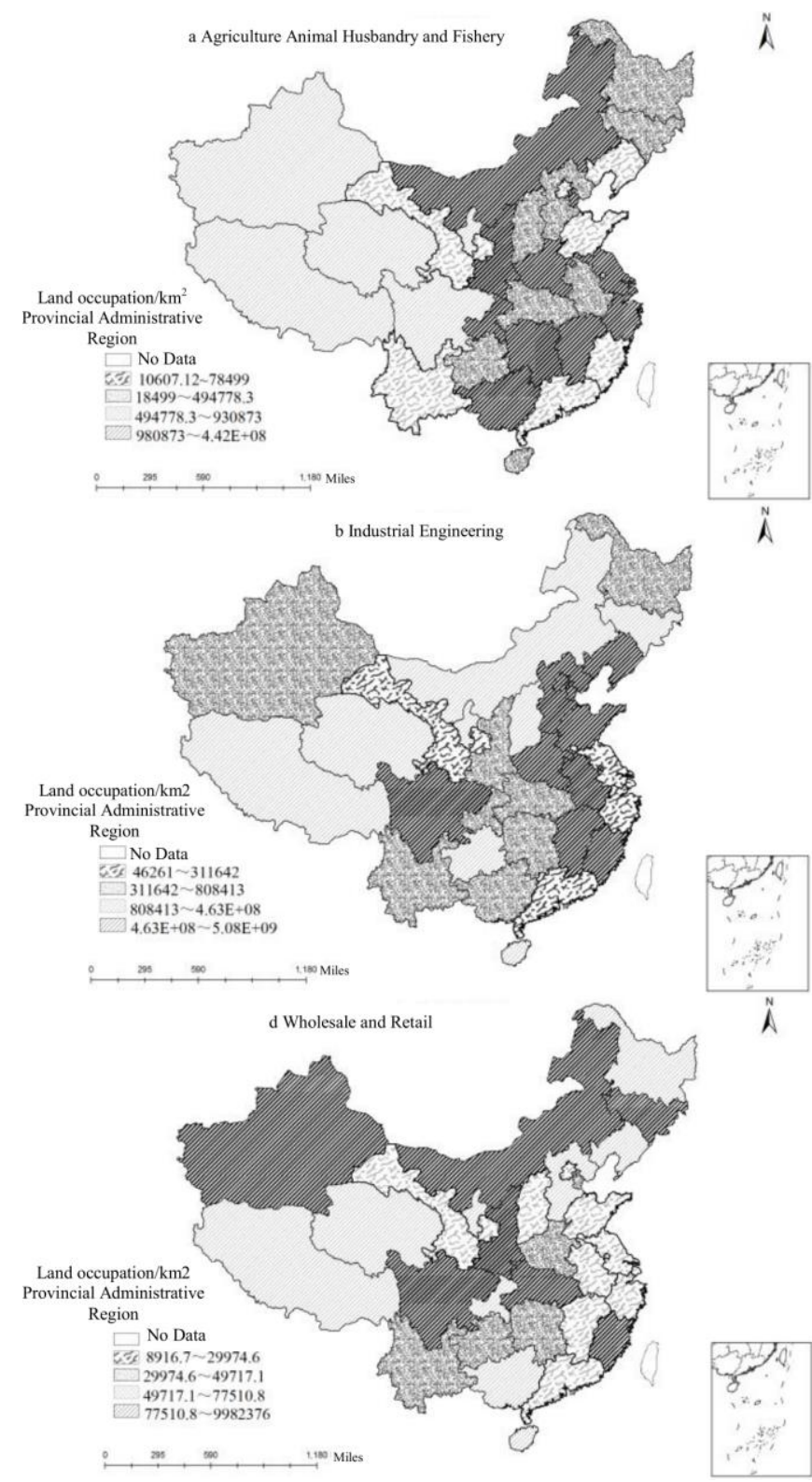




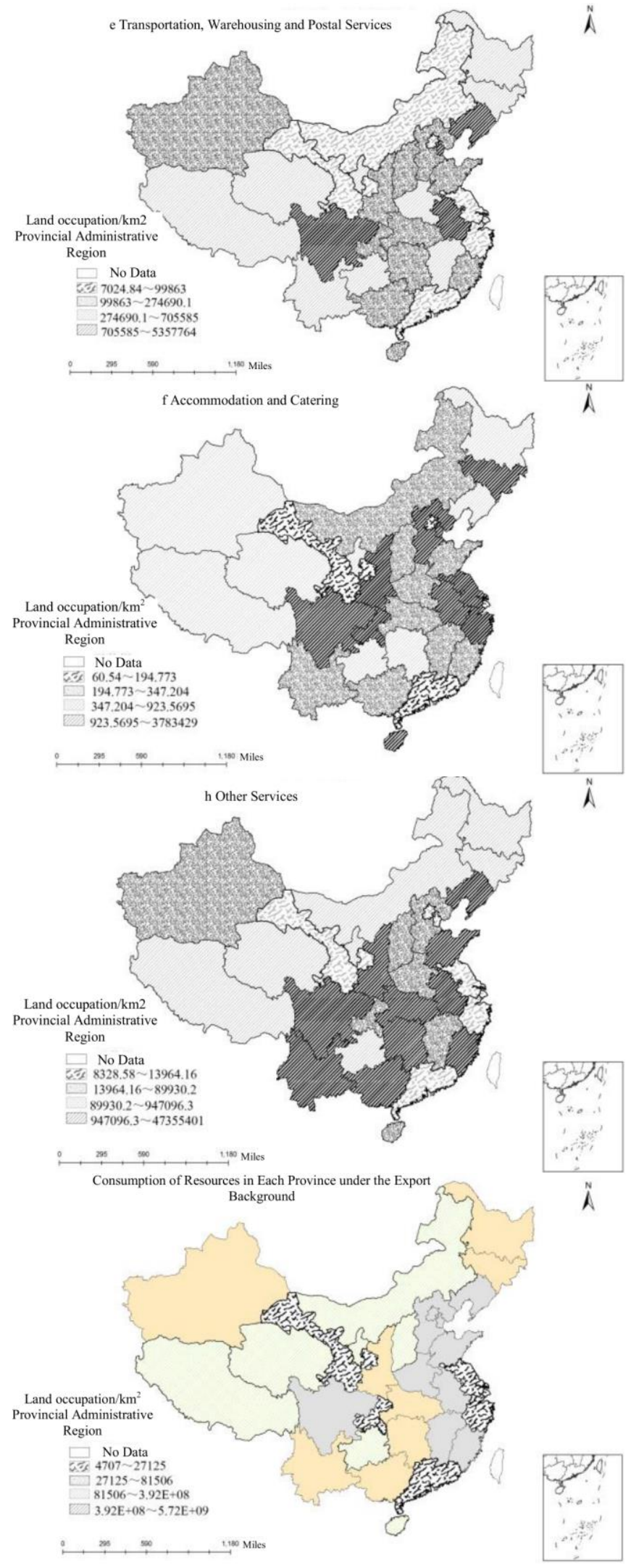

Fig. 3. Land resources occupancy induced by export and spatial distribution by sectors in Gansu province.

\section{The Amount of Land Resources Occupied by Gansu Province Caused by Exports}

From the background of exports, the occupational characteristics of industrial land resources in Gansu Province are shown in "Fig. 3". First, agriculture, forestry, animal husbandry and fishery are all types of occupied land resources. In the region, Fujian, Yunnan, Guangdong, Liaoning, Beijing, and Shandong have more occupations in Gansu Province, such as Qinghai, Ningxia, Xinjiang, Tibet, Shandong, Jiangxi, Inner Mongolia, Zhejiang, Fujian, Guangdong, and Sichuan. Gansu Province has a small amount of occupation, and the occupations in Guizhou, Hunan, Hainan, Hubei, Hebei, Shaanxi, Chongqing, Jilin, and Heilongjiang are in a moderate level. After analysis, due to the vast grassland in Inner Mongolia, Tibet and Qinghai, the animal husbandry industry has developed well. The oasis in Xinjiang is vast, and the climate environment is suitable for planting development. Shandong, Zhejiang, Guangdong and other places are located in coastal cities, and the water conservancy conditions are developed. Pleasant and mostly in plain locations, Jiangxi and Sichuan have mountainous agriculture with independent living characteristics, and they are exportable agricultural products at the border. Therefore, these provinces have less occupancy in Gansu Province. Second, industry is an occupational industry, and the basic heavy chemical industry in Gansu has developed more. The occupancy is more than other industries. Therefore, it can be seen from the map that Henan, Hebei, Jiangxi, Tianjin, Sichuan, Liaoning, Anhui, Beijing, Fujian, Shandong, Chongqing, Shanghai, Guangdong, Zhejiang, Jiangsu and other places have more occupation of Gansu Province, Qinghai, Ningxia, Hainan, Tibet, Shanxi, Inner Mongolia, Guizhou, Jilin and other places have less occupation. Third, the construction industry is occupied by land resources in areas with high economic development level and high population density. Fourth, in wholesale and retail, Jiangxi, Jiangsu, Anhui, Shanxi, Beijing, Guangdong, Zhejiang, and Shanghai have a large occupation of Gansu Province, and Ningxia, Hebei, Tibet, and Qinghai have relatively few occupations. Other provinces are in a moderate level. Fifth, transportation, warehousing and postal services and accommodation and catering have geographical differences. The occupancy of these two industries is related to factors such as economic development level and geographical advantages. The economic development level of Anhui, Zhejiang, Guangdong, Shanghai and Beijing is fast, and the occupation of Gansu Province is relatively high. The land resources of Gansu Province are higher in Guizhou, Tibet, Heilongjiang, Hunan, Xinjiang, Ningxia and Qinghai is less. Sixth, in information transmission, software and information technology services and other service industries, Tianjin, Zhejiang, Jiangsu, Beijing, Guangdong, and Shanghai, which have relatively fast economic development, have the largest occupancy in Gansu Province, followed by Hunan. In Hubei, Liaoning, Sichuan, Guangxi, Anhui, Shaanxi, Hainan, Shandong, and Fujian provinces, the remaining provinces are dominated by provinces such as Tibet, Guizhou, and Xinjiang. Generally speaking, the provinces with high economy level and important geographic location in the country, most of them are occupied by the transportation 
industry and warehousing industry, wholesale and retail industry and other service industries.

\section{Analysis and Policy Recommendations}

In general, under the scenario that different final demand such as export, consumption and investment lead to the occupation of land resources, there are certain inter-industry and regional differences in the occupation of land resources in Gansu Province by various provinces and industries. The specific performance is as follows: First, agriculture, forestry, animal husbandry and fishery are occupied ecological resources. In the context of exports, consumption, and investment, agriculture, forestry, animal husbandry and fishery in Gansu Province are more occupied than other industries. Therefore, it is considered in many existing studies that "the deprivation of agriculture is more vulnerable, and it is more encroached and deprived...." In the process of social development, agriculture is the foundation of the national economy. The development of agriculture is an important support for improving people's livelihood, increasing farmers' income and ensuring social stability, and the more underdeveloped areas, the proportion of agriculture in the regional industrial structure. It is relatively high, as a basic industry in regional development, and as a raw material for other industries such as industry, wholesale and retail, and other service industries. And the development of Gansu's agriculture plays an important role in the sustainable development of the entire western region. Therefore, the provinces should give certain compensation to the agriculture, forestry, animal husbandry and fishery in Gansu Province according to the amount of occupation. Second, industry belongs to the industry that occupies ecological resources. This is accompanied by the accelerating process of industrialization and urbanization in China. China has entered a period of rapid urbanization, and a series of regional deprivation behaviors have been derived from the rapid urbanization process. As seen in the investment scenario, the amount of industrial occupation in Gansu Province is still relatively large. It is due to the high energyconsuming industries such as energy and chemical industry, nonferrous metals and metallurgy in the large areas of Gansu Province, and they all account for a large proportion. Other places have provided raw materials for development, so a certain amount of compensation is paid for the ecological resources paid by Gansu Province. Third, the construction industry is an industry that occupies land resources in both consumption and exports. In the context of investment, Cities with high economic levels such as Hunan, Shaanxi, Heilongjiang, Beijing, Chongqing, Shanghai, Yunnan, and Jiangsu have more occupations in Gansu Province and should be compensated for a certain amount. In consumption and exports, the occupation of the construction industry in Gansu Province is zero. Fourth, in the wholesale and retail industry, the industry is mainly for consumers, and it should be an economically developed region with a wide distribution. In recent years, the online shopping industry has developed, and the products in the developed eastern regions have been continuously transmitted to the west, which has affected the wholesale and retail industries in the western regions (such as Gansu Province), so they should bear the responsibility for ecological compensation. Fifth, Transportation, warehousing and postal services and accommodation and catering are closely related to factors such as regional transportation development policies, better geographical conditions for transportation construction, superior geographical location, dense population and economic development. Therefore, most developed areas in the central and eastern regions occupy more resources in Gansu Province and belong to occupied industries. Sixth, Other service industries, in the context of investment, consumption, and exports, the service industry is an occupied industry.

Based on the above research conclusions and the results shown in the "Fig. 3", combined with the existing research results, this paper proposes the following policy recommendations. First, it's necessary to establish and improve the ecological compensation system and the corresponding accounting and assessment system. The government should appropriately cancel low level industries in Gansu province, high energy consumption, serious waste of resources and heavy pollution and implement heavy tax policy on their products; Encouraging the development of industries and products with low energy consumption and no pollution to implement zero tax rate [22]. Second, it follows the pattern of land resource occupation and regional differences among industries in China's provinces. From the perspective of regional relations, developed regions occupy the land resources of the service industry in underdeveloped regions; especially the service industry in economically developed provinces and cities should assume the responsibility of Gansu ecological compensation. Third, the government is still the dominant party in industrial ecological compensation and should fully reflect the government's responsibility at this stage. In the policy formulation of ecological compensation, it is necessary to focus on the central and western provinces, strengthen the legislation of industrial ecological compensation, and formulate necessary legislative measures of industrial ecological compensation. Fourth, it's important to strengthen the scientific research on the key technologies of provincial industrial ecological compensation standards, compensation objects, and compensation methods, so as to provide theoretical guidance for practical work.

\section{CONCLUSION}

This study uses the input-output method and regional relationship to construct a provincial ecological compensation framework, and proposes a corresponding calculation method. That is, it can judge individual resources from the occupation status of each industry at a single provincial level. The occupation of land resources within the province and between industries can further carry out ecological compensation between different provinces and regions at the national level.

Gansu Province belongs to the environmental lossreduction type of declining recession. Gansu Province is a coordinated development - ecological environment lag in spatial distribution. There are many restrictive factors for economic development in this region, but the large-scale 
chemical enterprises over-exploit resources in the early stage. As a result, the ecological environment of the area is relatively lagging behind. Therefore, from the perspective of various industrial types, the economically developed provinces are relatively "strong" deprived. They should pay a certain amount of compensation for ecological resources, so that the region can coordinate development.

Agriculture, forestry, animal husbandry and fishery, industry, construction, transportation and warehousing, wholesale and retail, accommodation and catering, information transmission, software and information technology services, and other services are in different situations of export, consumption and investment. The land resources occupied by them belong to different types, so the provincial differences in occupancy are relatively large. From the overall analysis, in the context of consumption and exports, Shanghai, Zhejiang, Jiangsu, Chongqing, Fujian, Guangdong, Beijing, Anhui, and other provinces with relatively fast economic development in the central and eastern regions have more occupation; Tibet. Xinjiang, Qinghai, Ningxia, Guizhou, Shanxi, and Guangxi, which are located in the west and have poor economic development, are less occupied; the remaining provinces are in the middle. In the case of investment, they are all occupational industries. Therefore, the provincial differences in occupancy are relatively large. Except for the negative occupancy of Beijing and Shanghai, the occupancy of other provinces is similar to that of consumption and export. Therefore, from the geographical analysis, the developed provinces and cities in the east should be more responsible for ecological compensation. The policy of ecological compensation should be tilted to Gansu Province, which makes the national economic region have a coordinate development.

Agriculture, forestry, animal husbandry and fishery, industry, construction, transportation and warehousing, wholesale and retail, accommodation and catering, information transmission, software and information technology services, and other services in different situations of export, consumption and investment. The type of land resource occupation to which it belongs is closely related to factors such as its level of socio-economic development, geographical area relationship, regional development policy, and its connection with other regions. Moreover, each province has an occupation relationship with each other, limited to research data and research methods. This paper doesn't describe the quantitative relationship between each other, and only analyzes the quantitative analysis of other provinces occupying Gansu Province. In theory, Gansu Province also occupies resources from other provinces. There should be a quantitative compensation between each other, and space display and expression in the form of maps, but limited to research data, research methods, etc., this study did not conduct in-depth analysis. These should be the focus of further research in the future.

\section{REFERENCES}

[1] Xie Lishuang. Reasons for the delay of industrial gradient transfer and the countermeasures in the west $[\mathrm{N}]$. Journal of the Central
University for Nationalities (Philosophy and Social Sciences), 2005, 32(5). (in Chinese)

[2] Wang Qiang, Wang Xiqun, Lu Shilei, Guo Baoxiang. The Economic Theoretical Basis of Ecological Compensation and China's Practice [J]. Forestry Economics, 2019, 41(01): 3-2. (in Chinese)

[3] Xu Zhongmin, Zhong Fanglei, Zhao Xueyan, Li Xingwen. A Review of Research Progress in Ecological Compensation [J]. Finance and Accounting Research, 2008(23): 67-72. (in Chinese)

[4] China Ecological Compensation Mechanism and Policy Research Group. 2007. China Ecological Compensation Mechanism and Policy Research [M]. Beijing Science Press. (in Chinese)

[5] Liu Chunla, Liu Weidong, Lu Dadao, Chen Mingxing, Xu Mei, Dong Xiaofeng.Analysis of the Differences of Provincial Ecological Compensation in China from 2004 to 2011 [J].Acta Geographica Sinica, 2015, 70(12):1897-1898. (in Chinese)

[6] Yu Wenlie. Studying the "CPC Central Committee's Decision on Several Major Issues in Comprehensively Deepening Reform" [A]. Foreign Economics and China Research Report (2014) [C].: China Foreign Economics Research Society, 2015: 4. (in Chinese)

[7] Li Xianzhan. Accelerate the formation of a new advantage for the development of Gansu's open economy [N]. Gansu Daily, 2019-01-29 (011). (in Chinese)

[8] Alix-Garcia J, De Janvry A, Sadoulet E. The role of deforestation risk and calibrated compensation in designing payments for environmental services $[\mathrm{J}]$. Environment and Development Economics, 2008, 13(3): 375-394.

[9] Zhao C W, Wang S J. Benefits and standards of ecologica compensation: International experiences and revelations for China $[\mathrm{J}]$. Geographical Research, 2010, 29(4): 597-606

[10] Mao Xianqiang, Zhong Yu, Zhang Sheng. Theoretical Discussion on Ecological Compensation [J]. China Population, Resources and Environment, 2002(04): 40-41. (in Chinese)

[11] Li Yong. Research on Ecological Compensation Charge Policy for Mineral Resources Development [D]. China Academy of Environmental Sciences, 2006. (in Chinese)

[12] Yin Chunrong. Research on Ecological Compensation Mechanism of Oil and Gas Resources Development [D]. Shandong Normal University, 2008. (in Chinese)

[13] Zhao Xueyan.Summary of research on ecological compensation efficiency [J]. Chinese Journal of Ecology, 2012, 32(6):1960-1969. (in Chinese)

[14] Zhou Le. 2011. Research on ecological compensation mechanism of mineral resources development in Hunan [D]. Beijing: China University of Geosciences. (in Chinese)

[15] Liu Moucheng, Lunfei, Zhang Canqiang, Li Wenhua. Determination of Ecological Compensation Standards for Rice Fields in Traditional Areas - Taking Hani Terraced Fields in Yunnan as an Example [J] Chinese Journal of Eco-Agriculture, 2012, 20(06): 703-705. (in Chinese)

[16] Liu Chunla, Liu Weidong, Lu Dadao, Tang Zhipeng. Research on China's Provincial Industrial Ecology Compensation Based on InputOutput Method [J]. Progress in Geography,2016,35(01):67-77. (in Chinese)

[17] ZhaoXueyan, Dong Xia, Fan Junjun, et al. Selection of ecological compensation methods for the water supply area of the Yellow River in Gannan [J]. Journal of Glaciology and Geocryology, 2010, 32(1): 204-210. (in Chinese)

[18] Shao Bo, Chen Xingpeng. Research on the Status Quo of Coordinated Development of Economy and Ecological Environment in Northwest China [J].Arid Land Geography, 2005(01):136-141. (in Chinese)

[19] Yang Shunshun, Song Chunyan, Xie Wei. Game Analysis of Ecological Compensation Subjects in Green Agricultural Products Industry [J]. Ecology and Economy, 2012(06):75-78. (in Chinese)

[20] Chen Gang, Liu Shanshan. Theoretical Research on Industria Transfer: Current Situation and Prospects [J]. Contemporary Finance and Economics, 2006 (10): 91-96. (in Chinese) 
[21] China Ecological Compensation Mechanism and Policy Research Group. 2007. China Ecological Compensation Mechanism and Policy Research [M]. Beijing Science Press. (in Chinese)

[22] China Ecological Compensation Mechanism and Policy Research Group. 2007. China Ecological Compensation Mechanism and Policy Research [M]. Beijing Science Press. (in Chinese)

[23] Wang Miaojie, Liu Jian, Wu Daqian, Gao Wei, Wang Renqing. Regional ecological compensation based on ecosystem service valu - Taking Shandong Province as an example [J]. Acta Ecologica Sinica, 2010, 30(23):6646- 6653. (in Chinese) 